\title{
Red blood cells and thrombin generation in sickle cell disease
}

\author{
Matthew F. Whelihan, Ming Y. Lim, and Nigel S. Key \\ Division of Hematology/Oncology, Department of Medicine, University of North Carolina at \\ Chapel Hill, USA
}

\section{Abstract}

The prothrombotic nature of sickle cell disease (SCD) is evidenced by the chronically elevated levels of almost all coagulation activation biomarkers, and an increased incidence of certain thrombotic events, including venous thromboembolism. Numerous studies have attempted to define the extent and elucidate the mechanism of the observed increase in thrombin generation in SCD patients in vivo. In general, these studies were performed using thrombin generation assays in platelet poor or platelet rich plasma and showed little difference in endogenous thrombin potential between the SCD cohort and healthy matched controls. In SCD, erythrocytes and monocytes have been demonstrated to exhibit procoagulant characteristics. Thus, the absence of these cellular components in standard thrombin generation assays may fail to reflect global hypercoagulability in the whole blood of patients with SCD. We were therefore surprised to see no difference in net thrombin generation in tissue factor-initiated initiated clotting of whole blood from patients with SCD. However, we are continuing to reconcile these seemingly disparate observations by slight modifications of the whole blood model that include alternative coagulation triggers and a re-examination of the net thrombin generation when the protein/protein $\mathrm{S}$ system is simultaneously interrogated.

\begin{abstract}
Approximately 1 in 625 African Americans are affected by sickle-cell disease (SCD) that is characterized by vaso-occlusive manifestations (including pain crises) and multiple end organ damage of varying severity [1]. Crises are generally ascribed to obstruction of the microvasculature secondary to adhesion of sickled red blood cells (RBCs) and other hematopoietic cellular elements. This process is followed by activation of coagulation and inflammatory pathways, as evidenced by the observation that patients with SCD typically manifest elevated plasma levels of thrombin-antithrombin (TAT) complexes, prothrombin fragment 1.2 (F1.2), and D-dimer [2, 3]. Furthermore, decreased levels of natural anticoagulant proteins, such as proteins C and S [4], as well as increased platelet activation [5] and increased numbers of circulating activated endothelial cells and monocytes
\end{abstract}

(C) 2014 Elsevier Ltd. All rights reserved.

Corresponding author: Nigel Key, Division of Hematology/Oncology, Department of Medicine, University of North Carolina at Chapel Hill, USA, nigel_key@med.unc.edu.

\section{Conflict of Interest}

The authors state that they have no conflicts of interest to declare.

Publisher's Disclaimer: This is a PDF file of an unedited manuscript that has been accepted for publication. As a service to our customers we are providing this early version of the manuscript. The manuscript will undergo copyediting, typesetting, and review of the resulting proof before it is published in its final citable form. Please note that during the production process errors may be discovered which could affect the content, and all legal disclaimers that apply to the journal pertain. 
expressing tissue factor also contribute to a systemic hypercoagulable state [6]. RBC sickling is central to the pathology of SCD. The repeated sickling and unsickling process as RBCs navigate the microvasculature leads not only to abnormal phosphatidylserine (PS) exposure, but also to an overall shortening of the RBC lifespan from $\sim 120$ to $\sim 20$ days. The ischemia-reperfusion cycle results in systemic inflammation with activation of leukocytes and endothelial cells. In turn, these events promote increased vessel wall permeability with neutrophil adhesion/migration into the inflamed tissues. Inflammatory cells produce cytokines including TNFa, IL-8 and IL-1 $\beta$ that activate vascular endothelial cells resulting in up-regulation of cellular adhesion molecules including intercellular adhesion molecule-1 (ICAM-1) and vascular cell adhesion molecule-1 (VCAM-1). This response further enhances the adhesiveness of inflammatory cells, platelets and sickled RBCs to endothelium [7]. These events collectively result in up-regulation of the idling threshold of thrombin generation; this impression is further corroborated by the clinical evidence for increased thrombotic events, such as venous thromboembolism (VTE) experienced by patients with $\operatorname{SCD}[1]$.

Several in vitro and ex vivo methodologies have been employed to examine thrombin generation potential in the peripheral blood of subjects with SCD. The most extensive studies of hypercoagulability in SCD have utilized (platelet rich or platelet poor) plasmabased thrombin generation assays. We recently summarized these data that have shown disparate results amongst six different laboratories with no conclusive evidence to suggest elevated thrombin generation potential in SCD by this approach [6]. The lack of standardization in plasma sample preparation and notorious inter-laboratory variability of these assays may have accounted for the inconsistent findings. Additionally, none of these studies specifically interrogated the protein $\mathrm{C}$ pathway (e.g. by addition of thrombomodulin). However, another report, not included in this study, did show activated protein $\mathrm{C}$ resistance when thrombomodulin was implemented [8]. Finally, the lack of erythrocytes and leucocytes in these assays likely fails to reflect the global hypercoagulability that may be present in whole blood in SCD, since almost all of the cellular components display procoagulant characteristics $[9,10]$.

One candidate contributor to thrombosis in SCD is the loss of normal membrane phospholipid asymmetry on sickled RBCs. Disruption of membrane phospholipid asymmetry results from repeated hypoxia-induced sickling and unsickling [11]. The exposure of anionic PS on the outer membrane results in a sub-population of prothrombotic RBCs that support the assembly of enzymatic clotting reactions [12,13]. Only two studies have specifically examined thrombin generation in the whole blood of patients with SCD. The first of these was by Yee et al. in 2005 utilizing thromboelastometry [14]. Compared to a group of healthy race-matched controls, the SCD cohort displayed a hypercoagulable state characterized by decreased $\mathrm{R}$ time coupled with an increase in the $\mathrm{a}$ angle. This study also found that blood obtained from HbSS patients during acute painful crises exhibited an increased maximum amplitude and coagulation index compared with HbSS patients at baseline. More recently, our laboratory evaluated thrombin generation in the whole blood of a small cohort of individuals with HbSS and race-matched controls [15]. Our methodology differed from that of TEG in that we measured thrombin generation as a function of its 
inhibition by its main stoichiometric inhibitor, antithrombin. Interestingly, the overall extent of a-thrombin-antithrombin (aTAT) generation did not differ significantly between the two groups; however, the rates of aTAT generation and consumption of prothrombin were increased in the HbSS cohort relative to controls. We also measured the rate of production of meizothrombin-antithrombin (mTAT) complexes that is indicative of thrombin generation on non-platelet surfaces, including red cells. The maximum level of mTAT produced in the HbSS cohort was approximately double that observed in the controls. Furthermore, we measured PS exposure on individual patient's RBC population by flow cytometry, and noted that the rate of mTAT formation was directly proportional to the number of PS-expressing RBCs for each group. Although there was no statistical difference in the absolute aTAT levels between the two groups, the higher rate of mIIa generation and prothrombin consumption observed in the HbSS patients, together with their much lower RBC numbers, suggests that in SCD, a much higher proportion of thrombin is generated on RBC surfaces.

The studies of TF-dependent thrombin generation outlined above suggest that only modest differences exist between $\mathrm{HbSS}$ and healthy controls, regardless of the methodology.

However, coagulation may be activated through either the TF-mediated (extrinsic) or the contact activation (intrinsic) pathways. It was shown many years ago that plasma levels of the contact factors (FXII, prekallikrein and high molecular weight kininogen) are reduced in patients with SCD, suggesting a consumptive process [16-18]. A recent study demonstrated that platelet and RBC-derived microparticles can initiate thrombin generation through FXIIa, presumably via a PS-mediated process [19]. Sickled RBCs not only shed microparticles (MP), but share many of their procoagulant properties. Thus, the question remains as to whether the increase in coagulation activation observed in SCD is initiated primarily through the extrinsic or intrinsic pathway with red cells and their shed MPs playing a key role in the latter. This possibility is further supported by other recent data from our laboratory which suggest that in a model of human endotoxemia, MP-dependent activation of coagulation is not mediated through the extrinsic pathway but rather through a FXI-dependent mechanism [20]. It should be noted that these observations do not exclude that cell-mediated activation of coagulation is dependent on tissue factor. Our current efforts are directed at ex vivo examination of contact pathway mediated thrombin generation in the whole blood of a larger cohort of individuals with SCD and race-matched controls. To accomplish this, we are employing the in vitro whole blood assay, TEG and plasma-based thrombin generation assays, both in the presence and absence of soluble thrombomodulin. Alternatively, the in vitro whole blood assay can be augmented by the addition of an endothelial monolayer which has also been shown to efficiently activate the protein $\mathrm{C}$ pathway [21]. Contact activation in each case is accomplished via native blood clotting in the absence of exogenous anticoagulants or extrinsic/intrinsic stimulators with thrombin generation and FXI activation being assessed via TAT and FXIa-AT/FXIa-C1 Esterase Inhibitor complex ELISA assays, respectively. Collectively, these tools will allow for a more in-depth examination of intrinsically activated thrombin generation in the whole blood of patients with sickle cell disease. 


\section{Acknowledgments}

The authors wish to acknowledge Kenneth Mann, $\mathrm{PhD}$ for his contributions to this work. MFW was supported by NIH grant T32-HL007149. MFW and NSK were supported by a Doris Duke Clinical Innovations Award. MYL was supported by ASH Research Training Award for Fellows.

\section{References}

1. Manwani D, Frenette PS. Vaso-occlusion in sickle cell disease: pathophysiology and novel targeted therapies. Blood. 2013; 122(24):3892-8. [PubMed: 24052549]

2. Tomer A, Harker LA, Kasey S, Eckman JR. Thrombogenesis in sickle cell disease. J Lab Clin Med. 2001; 137(6):398-407. [PubMed: 11385360]

3. Ataga KI, Key NS. Hypercoagulability in sickle cell disease: new approaches to an old problem. Hematology / the Education Program of the American Society of Hematology American Society of Hematology Education Program. 2007:91-6. [PubMed: 18024615]

4. Westerman MP, Green D, Gilman-Sachs A, Beaman K, Freels S, Boggio L, et al. Antiphospholipid antibodies, proteins C and S, and coagulation changes in sickle cell disease. J Lab Clin Med. 1999; 134(4):352-62. [PubMed: 10521081]

5. Lee SP, Ataga KI, Orringer EP, Phillips DR, Parise LV. Biologically active CD40 ligand is elevated in sickle cell anemia: potential role for platelet-mediated inflammation. Arterioscler Thromb Vasc Biol. 2006; 26(7):1626-31. [PubMed: 16601237]

6. Lim MY, Ataga KI, Key NS. Hemostatic abnormalities in sickle cell disease. Curr Opin Hematol. 2013; 20(5):472-7. [PubMed: 23817169]

7. Hebbel RP, Osarogiagbon R, Kaul D. The endothelial biology of sickle cell disease: inflammation and a chronic vasculopathy. Microcirculation. 2004; 11(2):129-51. [PubMed: 15280088]

8. van Beers EJ, Spronk HM, Ten Cate H, Duits AJ, Brandjes DP, van Esser JW, et al. No association of the hypercoagulable state with sickle cell disease related pulmonary hypertension.

Haematologica. 2008; 93(5):e42-4. [PubMed: 18450728]

9. Key NS, Slungaard A, Dandelet L, Nelson SC, Moertel C, Styles LA, et al. Whole blood tissue factor procoagulant activity is elevated in patients with sickle cell disease. Blood. 1998; 91(11): 4216-23. [PubMed: 9596669]

10. Setty BN, Rao AK, Stuart MJ. Thrombophilia in sickle cell disease: the red cell connection. Blood. 2001; 98(12):3228-33. [PubMed: 11719358]

11. Allan D, Limbrick AR, Thomas P, Westerman MP. Release of spectrin-free spicules on reoxygenation of sickled erythrocytes. Nature. 1982; 295(5850):612-3. [PubMed: 7057919]

12. Wood BL, Gibson DF, Tait JF. Increased erythrocyte phosphatidylserine exposure in sickle cell disease: flow-cytometric measurement and clinical associations. Blood. 1996; 88(5):1873-80. [PubMed: 8781447]

13. Zwaal RF, Schroit AJ. Pathophysiologic implications of membrane phospholipid asymmetry in blood cells. Blood. 1997; 89(4):1121-32. [PubMed: 9028933]

14. Yee DL, Edwards RM, Mueller BU, Teruya J. Thromboelastographic and hemostatic characteristics in pediatric patients with sickle cell disease. Archives of pathology \& laboratory medicine. 2005; 129(6):760-5. [PubMed: 15913424]

15. Whelihan MF, Mooberry MJ, Zachary V, Bradford RL, Ataga KI, Mann KG, et al. The contribution of red blood cells to thrombin generation in sickle cell disease: meizothrombin generation on sickled red blood cells. J Thromb Haemost. 2013

16. Gordon EM, Klein BL, Berman BW, Strandjord SE, Simon JE, Coccia PF. Reduction of contact factors in sickle cell disease. J Pediatr. 1985; 106(3):427-30. [PubMed: 3844465]

17. Miller RL, Verma PS, Adams RG. Studies of the kallikrein-kinin system in patients with sickle cell anemia. Journal of the National Medical Association. 1983; 75(6):551-6. [PubMed: 6603519]

18. Verma PS, Adams RG, Miller RL. Reduced plasma kininogen concentration during sickle cell crisis. Research communications in chemical pathology and pharmacology. 1983; 41(2):313-22. [PubMed: 6635322] 
19. Van Der Meijden PE, Van Schilfgaarde M, Van Oerle R, Renne T, ten Cate H, Spronk HM. Platelet- and erythrocyte-derived microparticles trigger thrombin generation via factor XIIa. J Thromb Haemost. 2012; 10(7):1355-62. [PubMed: 22537188]

20. Mooberry MJ, Bradford RL, FC L, EL H, Jilma B, Key NS. Procoagulant Microparticles Are Increased in Human Endotoxemia and Promote Coagulation in a FXI-Dependent Manner. 2013 Submitted.

21. Campbell JE, Brummel-Ziedins KE, Butenas S, Mann KG. Cellular regulation of blood coagulation: a model for venous stasis. Blood. 2010; 116(26):6082-91. [PubMed: 20864579] 